\title{
Effect of Azithromycin on Systemic Markers of Inflammation in Patients With Cystic Fibrosis Uninfected With Pseudomonas aeruginosa
}

\author{
Felix Ratjen, MD; Lisa Saiman, MD; Nicole Mayer-Hamblett, PhD; Larry C. Lands, MD, PhD; \\ Margaret Kloster, MS; Valeria Thompson, MS; Peggy Emmett, MA; Bruce Marshall, MD; \\ Frank Accurso, MD; Scott Sagel, MD; Michael Anstead, MD
}

\begin{abstract}
Background: While the mechanism of action by which azithromycin exerts positive effects in patients with cystic fibrosis remains unclear, evidence suggests that azithromycin may act as an immunomodulatory agent. We examined changes in systemic inflammatory markers in a doubleblind, randomized, controlled trial of oral azithromycin in patients 6-18 years of age with cystic fibrosis who were uninfected with Pseudomonas aeruginosa.

Methods: WBC counts and differential, serum myeloperoxidase (MPO), high-sensitivity C reactive protein (hsCRP), intracellular adhesion molecule 1, IL-6, calprotectin, serum amyloid A (SAA), and granulocyte colony-stimulating factor (G-CSF) were measured at baseline and after 28 and 168 days of treatment in patients receiving either oral azithromycin or placebo.

Results: Inflammatory markers were similar in both groups at baseline. HsCRP, MPO, SAA, calprotectin, and the absolute neutrophil count (ANC) significantly decreased from baseline to day 28 in the azithromycin group compared with the placebo group $(P<.05)$. This treatment effect was sustained at day 168 for ANC, calprotectin, and SAA $(P<.05)$. Changes in hsCRP, calprotectin, and SAA at day 28 were negatively correlated with changes in $\operatorname{FEV}_{1}(\mathrm{~L})$ and $F E V_{1}$ (\% predicted), as well as both absolute and relative changes in weight $(P<.05)$. Except for weight $(\%)$, the associations remained significant for calprotectin; $\mathrm{FEV}_{1}(\mathrm{~L})$ and weight $(\%)$ remained significantly correlated with the 168-day change in hsCRP. The 168-day change in ANC was significantly correlated with changes in lung function, but not in weight; the change in G-CSF was significantly correlated with the change in weight $(\%)$ only.

Conclusions: In patients not infected with $P$ aeruginosa, oral azithromycin significantly reduced neutrophil counts and serum inflammatory markers within 28 days of initiating treatment.

Trial registry: ClinicalTrials.gov; No.: NCT00431964; URL: www.clinicaltrials.gov
\end{abstract}

CHEST 2012; 142(5):1259-1266

Abbreviations: $\mathrm{ANC}=$ absolute neutrophil count; $\mathrm{CF}=$ cystic fibrosis; $\mathrm{G}-\mathrm{CSF}=$ granulocyte colony-stimulating factor; hsCRP = high-sensitivity $\mathrm{C}$ reactive protein; ICAM = intercellular adhesion molecule; LOD = limit of detection; $\mathrm{MPO}=$ myeloperoxidase; $\mathrm{SAA}=$ serum amyloid

$\mathrm{C}$ ystic fibrosis $(\mathrm{CF})$ is characterized by chronic airway infection and an excessive inflammatory response. ${ }^{1}$ Current treatment strategies include antibiotic therapy for intercurrent exacerbations and maintenance therapy with inhaled antibiotics for patients chronically infected with Pseudomonas aeruginosa. ${ }^{2}$ Azithromycin, a macrolide antibiotic, reduces pulmonary exacerbations and improves lung function in patients with $\mathrm{CF}$, but its mechanism of action is still unclear. ${ }^{3-6}$ Modulation of oxidant production by neutrophils and of proinflammatory cytokine synthesis and release by leukocytes are the two main effects observed in vitro. ${ }^{4-6}$ Macrolides accumulate within neutrophils and macrophages, and intracellular levels are markedly higher than extracellular levels. ${ }^{7} \mathrm{Mac}-$ rolides reduce proinflammatory cytokine production in vitro by neutrophils, monocytes, and bronchial epithelial cells presumptively via the ERK1/2 pathway. ${ }^{8-12}$ Macrolides may also reduce neutrophil accumulation by inhibiting intercellular adhesion molecule 
(ICAM)-1 on epithelial cell surfaces. ${ }^{13}$ In addition, macrolides could exert an antibiotic effect by reducing bacterial burden in the airways, which could indirectly reduce inflammation.

Multiple markers and techniques have been used to quantify airway inflammation in patients with CF. BAL is considered the gold standard, but its use in longitudinal studies is limited by the invasiveness of the procedure. ${ }^{14}$ Sputum is an alternative way of assessing material directly derived from the area of inflammatory activity, but both spontaneously expectorated- and induced-sputum parameters are highly variable, making inflammation difficult to track in patients over time. ${ }^{15}$ There has been a renewed interest in assessing systemic markers of inflammation. ${ }^{16,17}$ An important question is whether systemic biomarkers are sensitive enough to detect a meaningful change in lung disease, given that the inflammatory response to infection in $\mathrm{CF}$ is largely confined to the lung. Here, we studied a pediatric CF population with relatively mild disease and uninfected with $P$ aeruginosa, based on baseline pulmonary function, who participated in an intervention trial of oral azithromycin to assess the changes in circulating markers of inflammation during the 6-month study period.

\section{MATERIALS AND METHODS}

Details of the AZ0004 study have been described elsewhere. ${ }^{18}$ The trial was conducted at 31 Cystic Fibrosis Foundation-accredited care centers in the United States and at nine Canadian Cystic Fibrosis Foundation-accredited care centers coordinated by the CF Therapeutics Development Network Coordinating Center located in Seattle, Washington. Respective institutional review boards and ethics committees at each center approved the study and each participant and/or their parent voluntarily consented/assented

Manuscript received March 12, 2012; revision accepted April 23, 2012.

Affiliations: From the Division of Respiratory Medicine, Department of Pediatrics, and Program in Physiology and Experimental Medicine (Dr Ratjen), SickKids Research Institute, The Hospital for Sick Children, and University of Toronto, Toronto, ON, Canada; Department of Pediatrics (Dr Saiman), Columbia University, New York, NY; University of Washington (Dr Mayer-Hamblett and Mss Kloster and Thompson), Seattle, WA; Department of Pediatrics (Dr Lands), McGill University, Montreal, QC, Canada; University of Colorado School of Medicine (Drs Accurso and Sagel and Ms Emmett), Children's Hospital Colorado, Aurora, CO; Cystic Fibrosis Foundation (Dr Marshall), Bethesda, MD; and Children's Hospital (Dr Anstead), Lexington, KY.

Funding/Support: This research was funded by the Cystic Fibrosis Foundation, and grants from the National Institutes of Health/National Heart, Lung and Blood Institute [Grant 1 U01 HL081335-01] and National Center for Research Resources [Grant 1 UL1 RR025780].

Correspondence to: Felix Ratjen, MD, The Hospital for Sick Children, 555 University Ave, Toronto, ON, M5G 1X8, Canada; e-mail: felix.ratjen@sickkids.ca

(C) 2012 American College of Chest Physicians. Reproduction of this article is prohibited without written permission from the American College of Chest Physicians. See online for more details. DOI: $10.1378 /$ chest.12-0628 to participate in the trial (Hospital for Sick Children Research Ethics Board file number: 1000009573).

Eligibility criteria included a documented diagnosis of $\mathrm{CF}$, age 6 - 18 years, weight $\geq 18 \mathrm{~kg}, \mathrm{FEV}_{1} \geq 50 \%$ predicted, ${ }^{19}$ and respiratory cultures negative for $P$ aeruginosa for $\geq 1$ year. Exclusion criteria included the use of antibiotics, "high-dose" systemic steroids (defined as $\geq 1 \mathrm{mg} / \mathrm{kg}$ if participant's weight $<20 \mathrm{~kg}$ or $\geq 20 \mathrm{mg} / \mathrm{d}$ if participant's weight $\geq 20 \mathrm{~kg}$ ) within 14 days of screening; initiation of dornase alfa, ibuprofen, aerosolized antibiotics, or hypertonic saline within 30 days of screening; a positive respiratory culture for Burkholderia cepacia complex or nontuberculous mycobacteria; or any of the following laboratory abnormalities: $\gamma$-glutamyltransferase phosphate, aspartate serum transferase, or alanine transferase levels $\geq 2$ times the upper limit of normal; creatinine level $>1.5$ times the upper limit of normal for age; or absolute neutrophil count $(\mathrm{ANC}) \leq 1,000$.

Participants were randomized one-to-one to azithromycin or placebo, as outlined elsewhere. ${ }^{18}$ Clinical evaluations, physical examination, and spirometry were performed at days 0 (randomization), 28, 84, and 168. Blood samples to monitor complete and differential blood counts, liver function, and creatinine were obtained at screening and days 28 and 168. Serum and plasma samples were obtained at these time points, frozen at $-80^{\circ} \mathrm{C}$, and shipped to the core laboratory in Denver, Colorado, for analysis of inflammatory markers as detailed here. Data reported in this study are based on analyses of these samples.

Plasma and serum aliquots (depending on the analyte) were analyzed in the Cystic Fibrosis Foundation Mediator Core Laboratory in Aurora, Colorado, using validated assays for the following protein biomarkers: serum high-sensitivity $\mathrm{C}$ reactive protein (hsCRP) via immunonephelometry (Siemens Healthcare Diagnostics); plasma calprotectin via enzyme-linked immunosorbent assay (ALPCO Diagnostics); serum myeloperoxidase (MPO) via enzymelinked immunosorbent assay (CardioMPO, Cleveland HeartLab, Inc); serum amyloid A (SAA); serum granulocyte colony-stimulating factor (G-CSF), ICAM-1, and IL-6 (Luminex platform, Milliplex; EMD Millipore Corp). All assays were performed in duplicate, and mean values were used for analysis. ${ }^{15-17}$

\section{Statistical Analysis}

Due to the skewed distribution of the inflammatory markers, logarithmically transformed values were used. Values below the limit of detection (LOD) were assigned a value of one-half the lower LOD, and values above the upper LOD were assigned the upper LOD value. Means and corresponding 95\% CIs were summarized and graphically displayed at each visit and for changes over time. Two-sample $t$ tests evaluated at a two-sided .05 level of significance were used to test for differences between treatment groups in the 28- and 168-day change from baseline in each inflammatory marker.

Associations between baseline measurements of inflammatory markers and changes in weight ( $\mathrm{kg}$ and percentile) and lung function $\left(\mathrm{FEV}_{1} \mathrm{~L}\right.$ and \% predicted) over the 168 -day study were evaluated by Spearman correlation test with corresponding $95 \%$ CIs. Associations between the 28- and 168-day changes in inflammatory markers and the 28- and 168-day changes in clinical parameters during the course of the trial were similarly summarized. Proportions of subjects with inflammatory markers above the upper limit of the normal range were summarized by treatment group and study visit. Analyses were performed using R statistical package version 2.14.0 (R Foundation for Statistical Computing).

\section{RESULTS}

Of the 324 participants screened for the AZ0004 study, $260(80 \%)$ were randomized and treated; 131 
were randomized to azithromycin and 129 to placebo. ${ }^{18}$ Of the 260 participants, all had inflammatory marker laboratory results for MPO, hsCRP, ICAM-1, IL-6, G-CSF, calprotectin, SAA, and ANC, but a small fraction of test results could not be used due to hemolysis. Baseline characteristics were similar between treatment groups, including baseline weight ( $\mathrm{kg}$ and percentile), lung function $\left(\mathrm{FEV}_{1} \mathrm{~L}\right.$ and $\%$ predicted), and inflammatory markers (Table 1 ).18

Concentrations for ICAM- 1 and IL-6 were below the detection limit of the respective assays in the majority of participants and did not demonstrate any significant differences between treatment groups at the time points measured (data not shown). All other inflammatory markers were detectable in $>95 \%$ of participants. The 28- and 168-day changes in inflammatory markers from baseline are shown by treatment group in Table 1. Compared with placebo, the azithromycin group experienced a greater decline from baseline at day 28 in all inflammatory markers $(P<.05)$ except G-CSF $(P=.08)$. This treatment effect was sustained at day 168 in ANC, calprotectin, and SAA $(P<.05)($ Fig 1$)$.

The percentage of patients with measurements exceeding the upper limit of normal range is shown by visit in Table 2 . Twenty-four of the 125 azithromycin group participants (19\%) had calprotectin values above the normal range at baseline and only 12 of 118 azithromycin group participants (10\%) had values above the normal range at day 28 , but these proportions were not significantly different. A similar reduction in calprotectin levels was not seen in placebo participants. Similar trends were observed in SAA, hsCRP, and ANC.

Associations between baseline measurements of the inflammatory markers and 28- and 168-day changes in lung function and weight are shown in Fig 2. Except for ANC, which was negatively correlated with 168-day changes in weight ( $\mathrm{kg}$ ), no significant correlations were observed in this group of children with $\mathrm{CF}$ who had preserved lung function (mean [SD] baseline $\mathrm{FEV}_{1} 97.7$ [16.40] for the azithromycin group and 99.6 [13.65] for the placebo group).

Associations between 28-day changes in the measurements of inflammatory markers and 28-day changes in weight and lung function are shown in Fig 3A. Changes in hsCRP, calprotectin, and SAA at day 28 were negatively correlated with changes in $\mathrm{FEV}_{1}(\mathrm{~L})$ and $\mathrm{FEV}_{1}$ (\% predicted), as well as both absolute and relative changes in weight $(P<.05)$. In contrast, no significant associations were observed for MPO, G-CSF, and ANC.

Associations between 168-day changes in the measurements of inflammatory markers and 168-day changes in weight and lung function are shown in

Table 1-Baseline Concentrations and Changes in Inflammatory Markers in Patients Receiving Azithromycin or Placebo Over the 168-d Study Period

\begin{tabular}{|c|c|c|c|c|}
\hline Variable & Azithromycin Group & Placebo Group A & Treatment Effect (95\% CI) & $P$ Value \\
\hline \multicolumn{5}{|c|}{ Absolute neutrophil counts ${ }^{\mathrm{a}}$} \\
\hline Baseline & $0.64(0.19)$ & $0.63(0.18)$ & & $\ldots$ \\
\hline Day 28-baseline & $-0.10(0.22)$ & $0.01(0.20)$ & $-0.10(-0.15$ to -0.05$)$ & .0002 \\
\hline Day 168-baseline & $-0.05(0.23)$ & $0.01(0.20)$ & $-0.06(-0.12$ to -0.01$)$ & .0233 \\
\hline \multicolumn{5}{|l|}{$\mathrm{MPO},{ }^{\mathrm{a}} \mathrm{pmol} / \mathrm{L}$} \\
\hline Baseline & $2.87(0.33)$ & $2.82(0.27)$ & $\ldots$ & $\ldots$ \\
\hline Day 28-baseline & $-0.10(0.28)$ & $0.03(0.32)$ & $-0.13(-0.20$ to -0.05$)$ & .0015 \\
\hline Day 168-baseline & $-0.03(0.30)$ & $0.04(0.27)$ & $-0.07(-0.14$ to 0.00$)$ & .0601 \\
\hline \multicolumn{5}{|l|}{ hsCRP,a mg/L } \\
\hline Baseline & $-0.42(0.73)$ & $-0.47(0.67)$ & $\ldots$ & $\ldots$ \\
\hline Day 28-baseline & $-0.24(0.67)$ & $0.02(0.70)$ & $-0.26(-0.44$ to -0.09$)$ & .0033 \\
\hline Day 168-baseline & $-0.08(0.61)$ & $0.04(0.73)$ & $-0.12(-0.29$ to 0.05$)$ & .1779 \\
\hline \multicolumn{5}{|l|}{ Calprotectin, ${ }^{a} \mu \mathrm{g} / \mathrm{mL}$} \\
\hline Baseline & $0.35(0.33)$ & $0.33(0.31)$ & $\ldots$ & $\ldots$ \\
\hline Day 28-baseline & $-0.16(0.35)$ & $0.01(0.37)$ & $-0.17(-0.27$ to -0.08$)$ & .0003 \\
\hline Day 168-baseline & $-0.06(0.31)$ & $0.03(0.37)$ & $-0.09(-0.18$ to 0.00$)$ & .0455 \\
\hline \multicolumn{5}{|l|}{$\mathrm{G}-\mathrm{CSF},{ }^{\mathrm{a}} \mathrm{pg} / \mathrm{mL}$} \\
\hline Baseline & $1.61(0.37)$ & $1.67(0.38)$ & $\ldots$ & $\ldots$ \\
\hline Day 28-baseline & $-0.09(0.36)$ & $-0.01(0.37)$ & $-0.08(-0.18$ to 0.01$)$ & .0777 \\
\hline Day 168-baseline & $-0.09(0.33)$ & $-0.01(0.39)$ & $-0.07(-0.17$ to 0.02$)$ & .1178 \\
\hline \multicolumn{5}{|c|}{ Serum amyloid $\mathrm{A},{ }^{\mathrm{a}} \mathrm{ng} / \mathrm{mL}$} \\
\hline Baseline & $3.70(0.75)$ & $3.74(0.66)$ & $\ldots$ & $\ldots$ \\
\hline Day 28-baseline & $-0.24(0.81)$ & $0.01(0.68)$ & $-0.25(-0.44$ to -0.06$)$ & .0112 \\
\hline Day 168-baseline & $-0.10(0.68)$ & $0.09(0.73)$ & $-0.18(-0.36$ to 0.00$)$ & .0495 \\
\hline
\end{tabular}

Data given as mean (SD) unless otherwise indicated. G-CSF = granulocyte colony-stimulating factor; hsCRP = high-sensitivity $\mathrm{C}$ reactive protein $\mathrm{MPO}=$ myeloperoxidase.

a Data are $\log$ transformed. 


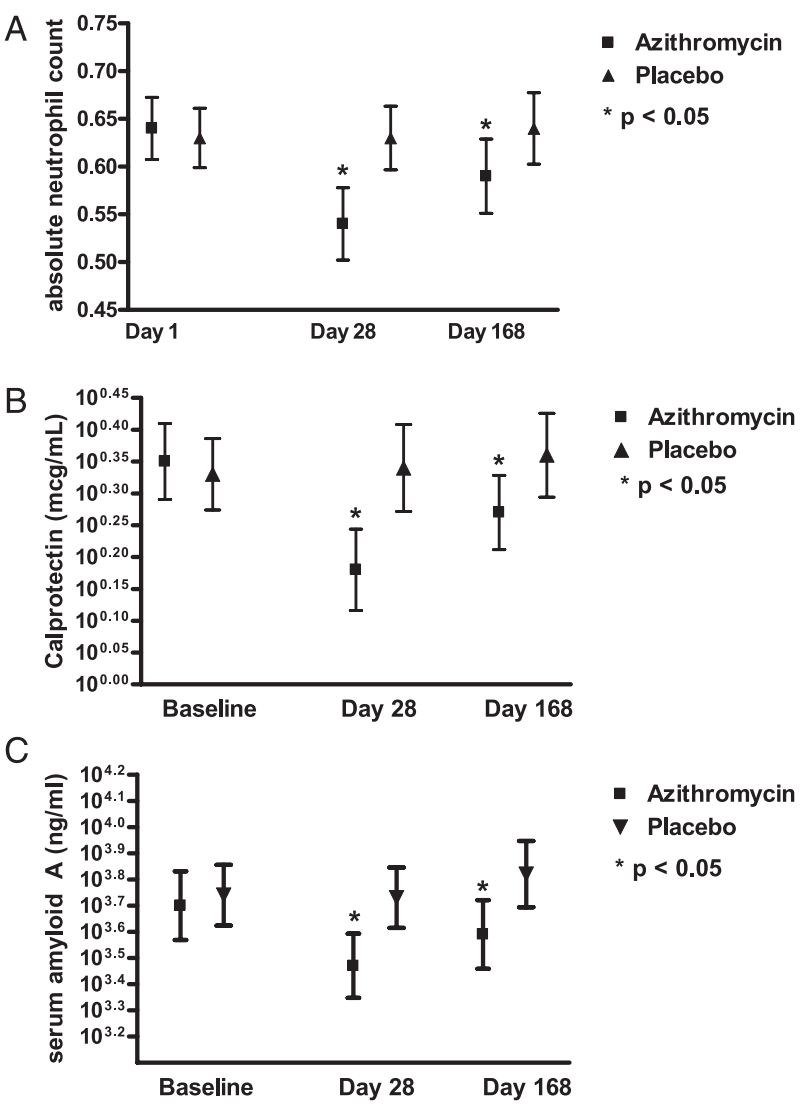

Figure 1. Changes in absolute neutrophil counts, serum amyloid A, and calprotectin during the 168-d study period. A, Absolute neutrophil counts. B, Calprotectin. C, Serum amyloid A. Absolute neutrophil counts, serum amyloid A, and calprotectin decreased significantly from baseline in the azithromycin group after $28 \mathrm{~d}$, while no significant changes were observed in the placebo group. The asterisk shows significant differences between the azithromycin and the placebo group. Similar trends were observed at day 168 , but the differences were less pronounced and reached the level of statistical significance only for calprotectin and serum amyloid A.

Fig 3B. Except for weight (\%), the associations remained significant for calprotectin; $\mathrm{FEV}_{1}(\mathrm{~L})$ and weight (\%) remained significantly correlated with 168-day change in hsCRP. The 168-day change in ANC was significantly correlated with changes in lung function, but not in weight; the change in G-CSF was significantly correlated with the change in weight $(\%)$ only.

\section{Discussion}

To the best of our knowledge, this is the first large study to assess the utility of a panel of systemic inflammatory markers in an interventional trial of patients with $\mathrm{CF}$ who have preserved lung function. Patients treated with azithromycin exhibited significant reductions in inflammatory markers after 4 weeks that persisted (albeit to a lesser degree) to week 24. Reduction in inflammatory markers were correlated to improvements in lung function and weight gain, providing indirect evidence that these changes were associated with clinically meaningful outcomes. These associations of changes in inflammatory markers with changes in lung function were seen despite the findings of the overall trial, which did not show a significant effect of azithromycin on lung function, but did show significant weight gain in the azithromycin group. ${ }^{18}$

Azithromycin has demonstrated clinical benefits in both children and adults with $\mathrm{CF}^{3,20-25}$ but its mechanism of action is unclear. Potential beneficial effects include antimicrobial effects, effect on sputum rheology, and direct effects on airway inflammation. Multiple in vitro studies have demonstrated that azithromycin can reduce production of proinflammatory cytokines and clinical effects could be observed in patients with bronchiolitis obliterans who do not usually have chronic bacterial infection. ${ }^{26-28}$ In the current trial, no changes were observed in microbiology except for an increase in Staphylococcus aureus and Haemophilus influenzae resistance to macrolides, common CF pathogens were not eradicated by azithromycin, and placebo participants did not have increased acquisition of CF pathogens. However, since most of the patients were unable to produce sputum, these data are based on qualitative, rather than quantitative, airway cultures. While this does not fully exclude the possibility that azithromycin had antimicrobial effects, these findings make it more likely that the observed effects are driven by the impact of azithromycin on airway inflammation, as suggested in previous studies. ${ }^{20-25}$

Azithromycin has been associated with reductions in CRP concentrations that were not observed in untreated patients. ${ }^{20,23,25}$ While patients enrolled in these previous trials had more significant lung disease compared with participants in the current study, reductions in CRP were also observed in patients with relatively mild disease. Interestingly, the effects on inflammatory markers were found to be more pronounced after 28 days compared with 168 days of treatment. This may suggest that treatment efficacy of azithromycin may decrease over time and raises the question of whether long-term continuous therapy, rather than intermittent therapy, is the optimal way to treat patients with CF. However, a study comparing clinical, rather than surrogate, outcomes for both treatment approaches would be required to test this hypothesis.

Systemic inflammatory markers in CF have largely been studied to diagnose and track patients during pulmonary exacerbations. These studies have shown that CRP is elevated in only a subgroup of patients, but previous studies may be limited by the use of CRP rather than hsCRP as an outcome parameter. ${ }^{29-32} \mathrm{Sim}$ ilarly, studies in patients with pulmonary exacerbations 
Table 2-Absolute Number and Percentage of Tests Above Upper Limit of Normal Range

\begin{tabular}{|c|c|c|c|c|c|c|}
\hline \multirow[b]{2}{*}{ Variable } & \multicolumn{2}{|c|}{ Baseline } & \multicolumn{2}{|c|}{ Day 28} & \multicolumn{2}{|c|}{ Day 168} \\
\hline & Azithromycin & Placebo & Azithromycin & Placebo & Azithromycin & Placebo \\
\hline ANC & $\begin{array}{r}11 / 131 \\
(8.4)\end{array}$ & $\begin{array}{r}8 / 128 \\
(6.3)\end{array}$ & $\begin{array}{r}3 / 121 \\
(2.5)\end{array}$ & $\begin{array}{r}8 / 125 \\
(6.4)\end{array}$ & $\begin{array}{r}11 / 123 \\
(8.9)\end{array}$ & $\begin{array}{r}14 / 122 \\
(11.5)\end{array}$ \\
\hline MPO & $\begin{array}{l}38 / 126 \\
(30.2)\end{array}$ & $\begin{array}{l}29 / 125 \\
\quad(23.2)\end{array}$ & $\begin{array}{l}23 / 122 \\
\quad(18.9)\end{array}$ & $\begin{array}{r}30 / 125 \\
(24.0)\end{array}$ & $\begin{array}{l}34 / 123 \\
\quad(27.6)\end{array}$ & $\begin{array}{c}(28.3) \\
12 / 118\end{array}$ \\
\hline hsCRP & $\begin{array}{l}16 / 126 \\
(12.7)\end{array}$ & $\begin{array}{r}9 / 126 \\
(7.1)\end{array}$ & $\begin{array}{r}7 / 119 \\
(5.9)\end{array}$ & $\begin{array}{r}12 / 125 \\
(9.6)\end{array}$ & $\begin{array}{r}11 / 123 \\
(8.9)\end{array}$ & $\begin{array}{c}\ldots \\
70 / 120\end{array}$ \\
\hline G-CSF & $\begin{array}{r}67 / 126 \\
(53.2)\end{array}$ & $\begin{array}{l}77 / 125 \\
\quad(61.6)\end{array}$ & $\begin{array}{l}53 / 121 \\
(43.8)\end{array}$ & $\begin{array}{r}68 / 125 \\
(54.4)\end{array}$ & $\begin{array}{l}52 / 122 \\
(42.6)\end{array}$ & $\begin{array}{l}(58.3) \\
\ldots\end{array}$ \\
\hline Calprotectin & $\begin{array}{l}24 / 125 \\
(19.2)\end{array}$ & $\begin{array}{r}24 / 126 \\
(19.0)\end{array}$ & $\begin{array}{c}12 / 118 \\
(10.2)\end{array}$ & $\begin{array}{l}23 / 125 \\
\quad(18.4)\end{array}$ & $\begin{array}{c}19 / 123 \\
(15.4)\end{array}$ & $\begin{array}{l}25 / 118 \\
\quad(21.2)\end{array}$ \\
\hline Serum amyloid A & $\begin{array}{r}32 / 126 \\
(25.4)\end{array}$ & $\begin{array}{l}29 / 124 \\
(23.4)\end{array}$ & $\begin{array}{r}18 / 121 \\
(14.9)\end{array}$ & $\begin{array}{r}30 / 125 \\
(24.0)\end{array}$ & $\begin{array}{r}30 / 123 \\
(24.4)\end{array}$ & $\begin{array}{r}39 / 120 \\
\quad(32.5)\end{array}$ \\
\hline
\end{tabular}

All data given as No. patients/total No. for whom the inflammatory marker measurement was made (\%). ANC = absolute neutrophil count. See Table 1 legend for expansion of other abbreviations.

have suggested that SAA and calprotectin may be useful markers to track inflammation in $\mathrm{CF}^{33,34}$ Interestingly, the current study demonstrates that a significant proportion of clinically stable patients with preserved lung function have inflammation that can be measured systemically, which supports BAL studies demonstrating persistent neutrophilic inflammation in clinically stable patients with CF. 35,36

To our knowledge, only one study has explored the utility of calprotectin as an inflammatory marker and demonstrated a correlation between changes in calprotectin and improvements in $\mathrm{FEV}_{1}$ during pulmonary exacerbations. ${ }^{34}$ This finding is supported by the current data, which show that calprotectin concentrations were not only correlated with baseline weight and lung function, but that reductions in calprotectin levels over time also correlated with improvements in weight and $\mathrm{FEV}_{1}$ after both 4 and 24 weeks of azithromycin therapy. This suggests that calprotectin may be superior to other inflammatory markers for tracking inflammation over time in patients with $\mathrm{CF}$ and that calprotectin could potentially be used as a marker of inflammation in interventional studies. While the functional role of calprotectin in $\mathrm{CF}$ is not well defined, calprotectin is produced by neutrophils and plasma levels are elevated during infection and inflammation. ${ }^{37}$ Calprotectin has antimicrobial effects; its mechanism of action is proposed to be that of a chelator of manganese and zinc ions, as it inhibits growth of $S$ aureus in vitro and in mice models of abscesses. ${ }^{38}$ Calprotectin also has antifungal activity, most notably as the major component of neutrophil extracellular traps. ${ }^{39}$ Calprotectin is also a ligand for toll-like receptor 4 , can stimulate $\mathrm{CD}^{+}{ }^{+}$cell-driven IL-17 production, and may, therefore, be important for the cross-talk between neutrophilic and lymphocytic inflammation, which has gained more interest in $\mathrm{CF}$ research. ${ }^{40-42}$

The current study has a number of important limitations. Systemic markers of inflammation are proxy surrogates of the inflammatory process in the airways and the sensitivity and specificity for these indirect markers is still unclear. While most patients with CF and normal lung function will have ongoing airway inflammation, the majority of patients in this study had baseline measurements within the normal range (Table 2), which likely explains why the difference in proportions for these parameters failed to be significant. This would suggest that the sensitivity of markers obtained in the blood might be lower than that of markers directly obtained from the airways. While BAL studies have demonstrated that neutrophilic inflammation in BAL predicts subsequent lung function decline, similar information is not available from prospective studies for systemic inflammatory markers. In addition, clinically meaningful thresholds for changes in these parameters are yet unknown. Longitudinal data tracking patients over time will be helpful in defining the utility of these markers in the clinic, as well as in clinical trials.

In summary, we demonstrated that azithromycin therapy in patients with preserved lung function who are not infected with $P$ aeruginos $a$ is associated with a reduction in systemic markers of inflammation. These effects were most pronounced after 28 days of treatment, but persisted over the 168-day treatment period and were noted for ANC, hsCRP, and calprotectin. Reductions in calprotectin levels over time correlated with improvements in weight and lung function, suggesting that these changes are linked to clinically meaningful outcomes. These data suggest that systemic markers of inflammation have added value and should be included in future CF clinical trials. 
A

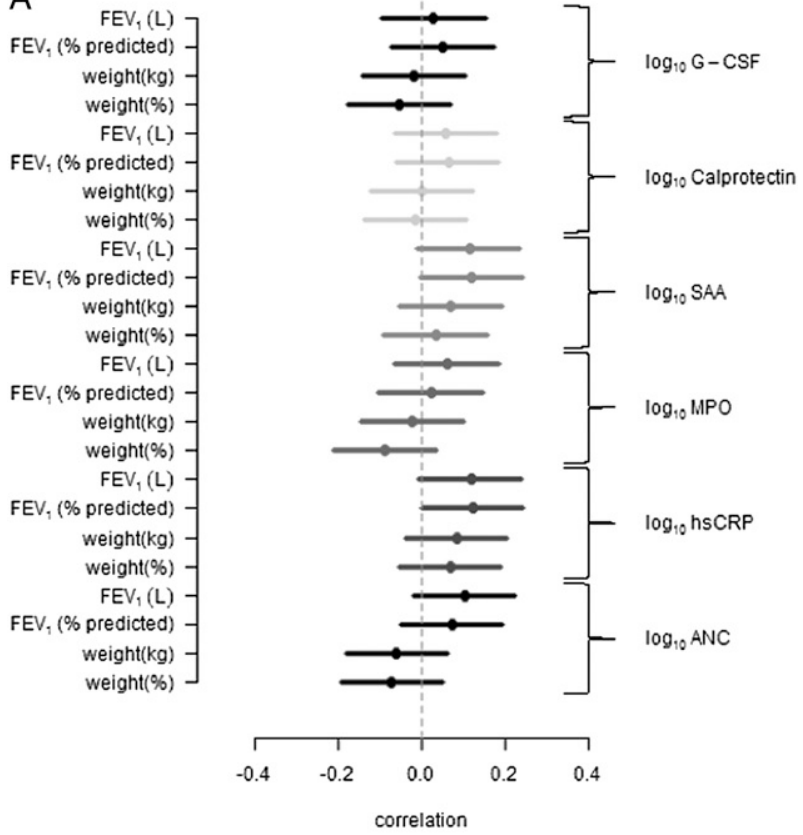

B

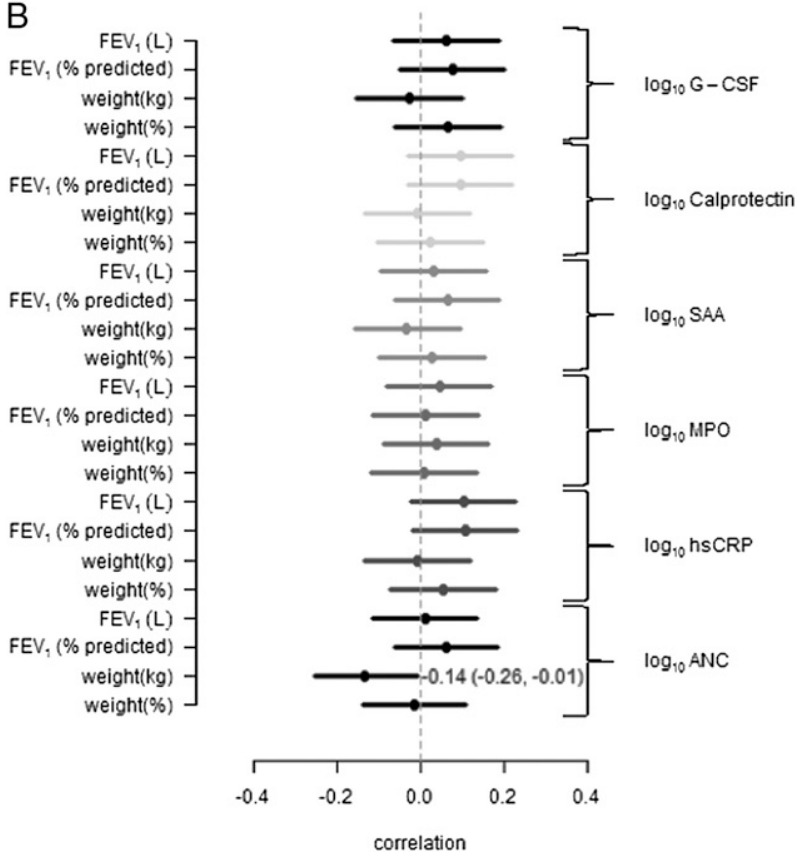

FigURE 2. Forest plot of correlations between baseline measures of inflammation and baseline $\mathrm{FEV}_{1}$ in $\mathrm{L}$ and \% predicted, as well as absolute and relative weight change. A, after $28 \mathrm{~d}$ of treatment. $\mathrm{B}$, After $168 \mathrm{~d}$ of treatment. The mean and $95 \%$ CI are shown for the correlations; correlations are significant if the CI does not cross zero. $\mathrm{ANC}=$ absolute neutrophil count; G-CSF = granulocyte colony-stimulating factor; hsCRP $=$ high-sensitivity $\mathrm{C}$ reactive protein $\mathrm{MPO}=$ myeloperoxidase $\mathrm{SAA}=$ serum amyloid.

\section{ACKNOWLEDGMENTS}

Author contributions: Dr Ratjen is the guarantor of the manuscript and takes responsibility for the integrity of the data and the accuracy of the data analysis.

Dr Ratgen: contributed to conception and design of the study; data acquisition, analysis, and interpretation; writing or revising
A

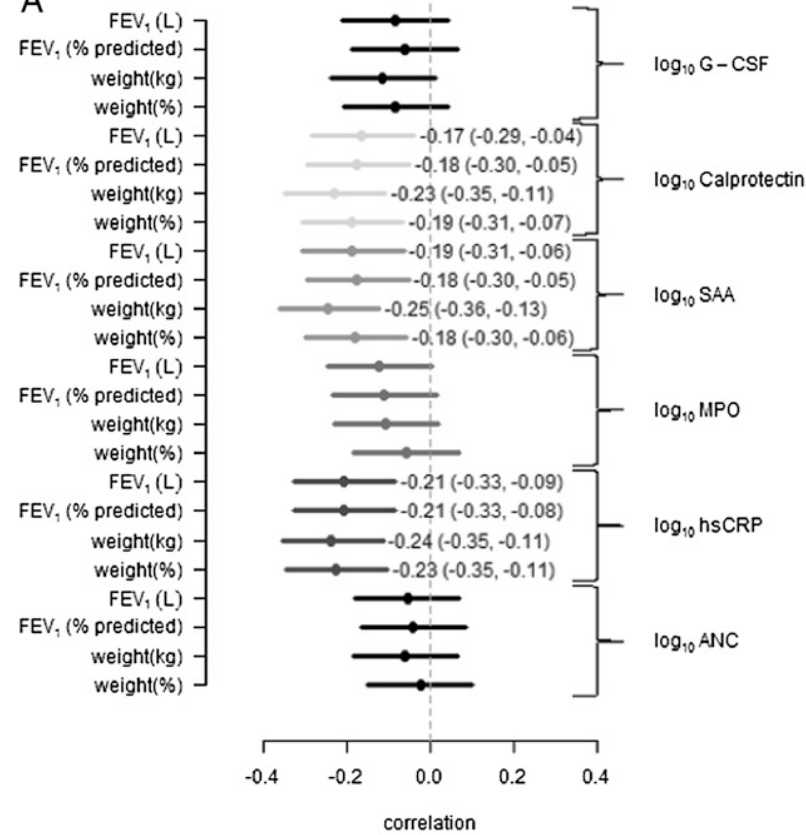

B

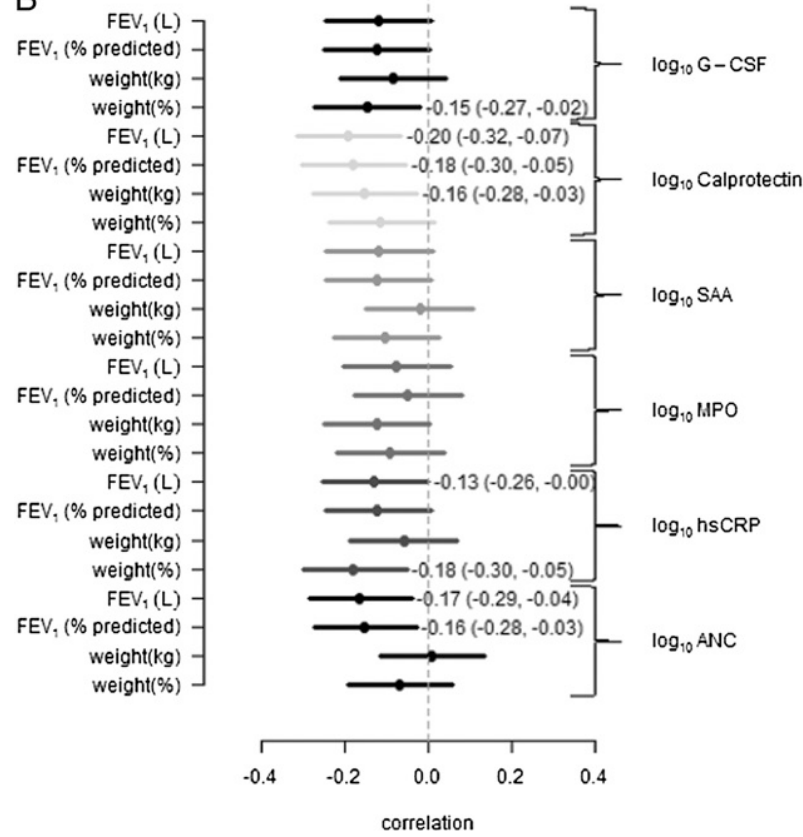

FiguRE 3. Forest plot of correlations changes in markers of inflammation and $\mathrm{FEV}_{1}$ in $\mathrm{L}$ and \% predicted, as well as absolute and relative weight change. A, At day 28. B, At day 168. The mean and $95 \%$ CI of the correlations are shown; correlations are significant if the CI does not cross zero. See Figure 2 legend for expansion of abbreviations.

the final manuscript for important intellectual content; and approval of the final manuscript; and served as principal author. Dr Saiman: contributed to conception and design of the study; data acquisition, analysis, and interpretation; writing or revising the final manuscript for important intellectual content; and approval of the final manuscript.

Dr Mayer-Hamblett: contributed to conception and design of the study; data acquisition, analysis, and interpretation; writing or revising the final manuscript for important intellectual content; and approval of the final manuscript. 
Dr Lands: contributed to conception and design of the study; data acquisition, analysis, and interpretation; writing or revising the final manuscript for important intellectual content; and approval of the final manuscript.

Ms Kloster: contributed to data analysis and interpretation, writing or revising the final manuscript for important intellectual content, and approval of the final manuscript.

Ms Thompson: contributed to data analysis and interpretation, writing or revising the final manuscript for important intellectual content, and approval of the final manuscript.

Ms Emmett: contributed to data acquisition, writing or revising the final manuscript for important intellectual content, and approval of the final manuscript.

Dr Marshall: contributed to conception and design of the study, data analysis and interpretation, writing or revising the final manuscript for important intellectual content, and approval of the final manuscript.

Dr Accurso: contributed to data acquisition, writing or revising the final manuscript for important intellectual content, and approval of the final manuscript.

Dr Sagel: contributed to data acquisition, writing or revising the final manuscript for important intellectual content, and approval of the final manuscript.

Dr Anstead: contributed to conception and design of the study; data acquisition, analysis, and interpretation; writing or revising the final manuscript for important intellectual content; and approval of the final manuscript.

Financial/nonfinancial disclosures: The authors have reported the following conflicts of interest: Dr Ratjen has received funding from the Canadian Institutes of Health Research, National Institutes of Health, Cystic Fibrosis Foundation, and Cystic Fibrosis Canada. He also acts as a consultant for Bayer AG; Genentech, Inc; Novartis AG; Talecris; and Vertex Pharmaceuticals Inc. The remaining authors have reported that no potential conflicts of interest exist with any companies/organizations whose products or services may be discussed in this article

Role of sponsors: The sponsors had no role in the design of the study, the collection and analysis of the data, or in the preparation of the manuscript.

\section{REFERENCES}

1. Ratjen F, Döring G. Cystic fibrosis. Lancet. 2003;361(9358): 681-689.

2. Flume PA, Mogayzel PJ Jr, Robinson KA, Rosenblatt RL, Quittell L, Marshall BC; Clinical Practice Guidelines for Pulmonary Therapies Committee; Cystic Fibrosis Foundation Pulmonary Therapies Committee. Cystic fibrosis pulmonary guidelines: pulmonary complications: hemoptysis and pneumothorax. Am J Respir Crit Care Med. 2010;182(3):298-306.

3. Southern KW, Barker PM, Solis-Moya A, Patel L. Macrolide antibiotics for cystic fibrosis. Cochrane Database Syst Rev. 2011;12(12):CD002203.

4. Labro MT. Cellular and molecular effects of macrolides on leukocyte function. Curr Pharm Des. 2004;10(25):3067-3080.

5. Tamaoki J, Kadota J, Takizawa H. Clinical implications of the immunomodulatory effects of macrolides. Am J Med. 2004; 117(Suppl 9A):5S-11S.

6. Parnham MJ, Culi O, Erakovi V, et al. Modulation of neutrophil and inflammation markers in chronic obstructive pulmonary disease by short-term azithromycin treatment. Eur J Pharmacol. 2005;517(1-2):132-143.

7. Miller MF, Martin JR, Johnson P, Ulrich JT, Rdzok EJ, Billing P. Erythromycin uptake and accumulation by human polymorphonuclear leukocytes and efficacy of erythromycin in killing ingested Legionella pneumophila. J Infect Dis. 1984;149(5):714-718.

8. Shinkai M, Foster GH, Rubin BK. Macrolide antibiotics modulate ERK phosphorylation and IL-8 and GM-CSF production by human bronchial epithelial cells. Am J Physiol Lung Cell Mol Physiol. 2006;290(1):L75-L85.

9. Cigana C, Nicolis E, Pasetto M, Assael BM, Melotti P. Antiinflammatory effects of azithromycin in cystic fibrosis airway epithelial cells. Biochem Biophys Res Commun. 2006;350(4): 977-982

10. Cigana C, Assael BM, Melotti P. Azithromycin selectively reduces tumor necrosis factor alpha levels in cystic fibrosis airway epithelial cells. Antimicrob Agents Chemother. 2007; 51(3):975-981.

11. Meyer M, Huaux F, Gavilanes X, et al. Azithromycin reduces exaggerated cytokine production by $\mathrm{M} 1$ alveolar macrophages in cystic fibrosis. Am J Respir Cell Mol Biol. 2009;41(5): 590-602.

12. Bergamini G, Cigana C, Sorio C, et al. Effects of azithromycin on glutathione S-transferases in cystic fibrosis airway cells. Am J Respir Cell Mol Biol. 2009;41(2):199-206.

13. Hillis GS, Pearson CV, Harding SA, et al. Effects of a brief course of azithromycin on soluble cell adhesion molecules and markers of inflammation in survivors of an acute coronary syndrome: A double-blind, randomized, placebo-controlled study. Am Heart J. 2004;148(1):72-79.

14. Davis SD, Brody AS, Emond MJ, Brumback LC, Rosenfeld M. Endpoints for clinical trials in young children with cystic fibrosis. Proc Am Thorac Soc. 2007;4(4):418-430.

15. Sagel SD, Chmiel JF, Konstan MW. Sputum biomarkers of inflammation in cystic fibrosis lung disease. Proc Am Thorac Soc. $2007 ; 4(4): 406-417$.

16. Saavedra MT, Hughes GJ, Sanders LA, et al. Circulating RNA transcripts identify therapeutic response in cystic fibrosis lung disease. Am J Respir Crit Care Med. 2008;178(9): 929-938

17. Laguna TA, Wagner BD, Luckey HK, et al. Sputum desmosine during hospital admission for pulmonary exacerbation in cystic fibrosis. Chest. 2009;136(6):1561-1568.

18. Saiman L, Anstead M, Mayer-Hamblett N, et al; AZ0004 Azithromycin Study Group. Effect of azithromycin on pulmonary function in patients with cystic fibrosis uninfected with Pseudomonas aeruginosa: a randomized controlled trial. JAMA. 2010;303(17):1707-1715.

19. Wang X, Dockery DW, Wypij D, et al. Pulmonary function growth velocity in children 6 to 18 years of age. Am Rev Respir Dis. 1993;148(6 pt 1):1502-1508.

20. Wolter J, Seeney S, Bell S, Bowler S, Masel P, McCormack J. Effect of long term treatment with azithromycin on disease parameters in cystic fibrosis: a randomised trial. Thorax. 2002;57(3):212-216.

21. Equi A, Balfour-Lynn IM, Bush A, Rosenthal M. Long term azithromycin in children with cystic fibrosis: a randomised, placebo-controlled crossover trial. Lancet. 2002;360(9338): 978-984.

22. Saiman L, Marshall BC, Mayer-Hamblett N, et al; Macrolide Study Group. Azithromycin in patients with cystic fibrosis chronically infected with Pseudomonas aeruginosa: a randomized controlled trial. JAMA. 2003;290(13):1749-1756.

23. Hansen CR, Pressler T, Koch C, Høiby N. Long-term azitromycin treatment of cystic fibrosis patients with chronic Pseudomonas aeruginosa infection; an observational cohort study. J Cyst Fibros. 2005;4(1):35-40.

24. Clement A, Tamalet A, Leroux E, Ravilly S, Fauroux B, Jais JP. Long term effects of azithromycin in patients with cystic fibrosis: A double blind, placebo controlled trial. Thorax. 2006;61(10):895-902.

25. Steinkamp G, Schmitt-Grohe S, Döring G, et al. Once-weekly azithromycin in cystic fibrosis with chronic Pseudomonas aeruginosa infection. Respir Med. 2008;102(11):1643-1653. 
26. Zarogoulidis P, Papanas N, Kioumis I, Chatzaki E, Maltezos E, Zarogoulidis K. Macrolides: from in vitro anti-inflammatory and immunomodulatory properties to clinical practice in respiratory diseases. Eur J Clin Pharmacol. 2012;65(5): 479-503.

27. Gerhardt SG, McDyer JF, Girgis RE, Conte JV, Yang SC, Orens JB. Maintenance azithromycin therapy for bronchiolitis obliterans syndrome: results of a pilot study. Am J Respir Crit Care Med. 2003;168(1):121-125.

28. Verleden GM, Vanaudenaerde BM, Dupont LJ, Van Raemdonck DE. Azithromycin reduces airway neutrophilia and interleukin-8 in patients with bronchiolitis obliterans syndrome. Am J Respir Crit Care Med. 2006;174(5):566-570.

29. Friesen CA, Wiens LA, Burry VF, Portnoy J, Roberts CC. C-reactive protein in acute pulmonary exacerbations of patients with cystic fibrosis. Pediatr Pulmonol. 1995;20(4):215-219.

30. Levy H, Kalish LA, Huntington I, et al. Inflammatory markers of lung disease in adult patients with cystic fibrosis. Pediatr Pulmonol. 2007;42(3):256-262.

31. Smith JW, Colombo JL, McDonald TL. Comparison of serum amyloid A and C-reactive protein as indicators of lung inflammation in corticosteroid treated and non-corticosteroid treated cystic fibrosis patients. J Clin Lab Anal. 1992;6(4):219-224.

32. McGrath LT, Mallon P, Dowey L, et al. Oxidative stress during acute respiratory exacerbations in cystic fibrosis. Thorax. 1999;54(6):518-523.

33. Marhaug G, Permin H, Husby G. Amyloid-related serum protein (SAA) as an indicator of lung infection in cystic fibrosis. Acta Paediatr Scand. 1983;72(6):861-866.

34. Gray RD, Imrie M, Boyd AC, Porteous D, Innes JA, Greening AP. Sputum and serum calprotectin are useful biomarkers during CF exacerbation. J Cyst Fibros. 2010;9(3): 193-198.

35. Konstan MW, Hilliard KA, Norvell TM, Berger M. Bronchoalveolar lavage findings in cystic fibrosis patients with stable, clinically mild lung disease suggest ongoing infection and inflammation. Am J Respir Crit Care Med. 1994;150(2): 448-454.

36. Paul K, Rietschel E, Ballmann M, et al; Bronchoalveolar Lavage for the Evaluation of Antiinflammatory Treatment Study Group. Effect of treatment with dornase alpha on airway inflammation in patients with cystic fibrosis. Am J Respir Crit Care Med. 2004;169(6):719-725.

37. Stríz I, Trebichavský I. Calprotectin-a pleiotropic molecule in acute and chronic inflammation. Physiol Res. 2004;53(3): 245-253.

38. Corbin BD, Seeley EH, Raab A, et al. Metal chelation and inhibition of bacterial growth in tissue abscesses. Science. 2008;319(5865):962-965.

39. Urban CF, Ermert D, Schmid M, et al. Neutrophil extracellular traps contain calprotectin, a cytosolic protein complex involved in host defense against Candida albicans. PLoS Pathog. 2009;5(10):e1000639.

40. Loser K, Vogl T, Voskort M, et al. The Toll-like receptor 4 ligands Mrp8 and Mrp14 are crucial in the development of autoreactive CD8+ T cells. Nat Med. 2010;16(6):713-717.

41. Thewissen M, Damoiseaux J, van de Gaar J, Tervaert JW. Neutrophils and T cells: bidirectional effects and functional interferences. Mol Immunol. 2011;48(15-16):2094-2101.

42. Tan HL, Regamey N, Brown S, Bush A, Lloyd CM, Davies JC. The Th17 pathway in cystic fibrosis lung disease. Am J Respir Crit Care Med. 2011;184(2):252-258. 